\title{
PRINSIP-PRINSIP TRANSFORMASI KEBIJAKAN PEMBANGUNAN BERKELANJUTAN DAN PENGENDALIAN PERUBAHAN IKLIM BERDASARKAN PARADIGMA SYSTEMS THINKING
}

\author{
(Principles of Transformation Policy of Sustainable Development and Climate Change \\ Countermeasure Based on Systems Thinking Paradigm)
}

\author{
Mahawan Karuniasa \\ Program Studi Ilmu Lingkungan, Sekolah Ilmu Lingkungan, Universitas Indonesia \\ Kampus UI Salemba \\ Jl. Salemba Raya 4, Jakarta, 10430, Indonesia \\ E-mail: mahawan.karuniasal1@ui.ac.id
}

Diterima: 21 November 2019, Direvisi: 27 November 2019, Disetujui: 31 Desember 2019

DOI: https://doi.org/10.31849/forestra

\begin{abstract}
The global development has resulted social and environmental issues, including climate change. After the Silent Spring and Brundtland Report publicated, global development paradigm has changed to sustainable development. National development continues to support the growing population for moving forward into developed country. Nevertheless, the national development undertaken showed an unsustainable development pattern. This research aimed to obtain the principles of transformation sustainable development and climate change policy in Indonesia used Soft System Methodology. Reflections on sustainable development and climate change countermeasure showed that national development was economic-oriented and left environmental quality, green house gas pattern has been moving toward business-as-usual conditions. The principles of policy transformation to realize the sustainable development and climate change countermeasure in Indonesia, the paradigm, from static to a dynamic and holistic of Systems Thinking paradigm, especially for stakeholders and decision makers. It necessary to build awareness and operational actions of stakeholders, including the government institutions, that Law Nomor 32 Year 2009 on Environmental Protection and Management context of sustainable development to achieve sustainable Indonesia. To face global issues, such as climate change and sustainable development goals, need to constructed according to economic, social and environmental.
\end{abstract}

Keywords: Climate change, Policy, Sustainable development, Systems thinking 


\begin{abstract}
ABSTRAK
Pembangunan global dengan mengedepankan ekonomi mengakibatkan permasalahan sosial dan lingkungan, termasuk perubahan iklim. Terbitnya buku the Silent Spring, dan Brundtland Report, mengubah paradigma global, menuju pembangunan berkelanjutan, termasuk Indonesia. Pembangunan nasional dilakukan untuk mendukung pertumbuhan penduduk dan untuk menjadi negara maju, namun berpola tidak berkelanjutan. Penelitian ditujukan untuk memperoleh prinsip transformasi kebijakan pembangunan bekelanjutan dan pengendalian perubahan iklim di Indonesia dengan Soft System Methodology yang disederhanakan. Refleksi pembangunan berkelanjutan dan pengendalian perubahan iklim menunjukkan pembangunan berorientasi ekonomi, kurang memperhatikan lingkungan, dan pola emisi gas rumah kaca masih menuju kondisi business as usual. Prinsip transformasi kebijakan untuk mewujudkan tujuan pembangunan berkelanjutan dan pengendalian perubahan iklim di Indonesia yaitu perubahan paradigma, dari parsial/sektoral (statis dan sesaat) menjadi paradigma Systems Thinking (holistik dan dinamis), khususnya untuk pemangku kepentingan, terutama pengambil keputusan di pemerintahan. Perlu dibangun kesadaran dan tindakan operasional pemangku kepentingan, termasuk pemerintah, bahwa Undang-Undang Nomor 32 Tahun 2009 tentang Perlindungan dan Pengelolaan Lingkungan Hidup untuk mewujudkan Indonesia berkelanjutan. Dalam menghadapi isu global, seperti perubahan iklim dan pembangunan berkelanjutan perlu dikonstruksikan sesuai kondisi ekonomi, sosial, dan lingkungan.
\end{abstract}

Kata Kunci: Kebijakan, Pembangunan berkelanjutan, Perubahan iklim, Systems thinking

\section{PENDAhuluan}

Banyak definisi ilmiah tentang pembangunan, namun pembangunan secara sederhana dapat diartikan sebagai upaya untuk memperoleh berbagai aspek kehidupan yang lebih baik bagi semua orang (Peet \& Hartwick, 2009). Artinya, keseluruhan atau setiap upaya untuk meningkatkan aspek-aspek kehidupan seperti kesehatan, pendidikan, pendapatan, kebahagiaan, kondisi lingkungan, dan lainnya dapat dinyatakan pembangunan, namun dengan syarat, yaitu ditujukan untuk semua orang. Upaya meningkatkan pendapatan sekelompok orang dan mengakibatkan berkurangnya pendapatan atau menganggu kesehatan sekelompok orang lainnya, tidak dapat dikatakan sebagai pembangunan.

Ilmu tentang pembangunan terus berkembang bersamaan dengan proses pembangunan. Kegagalan pembangunan menghasilkan konsep dan teori baru tentang pembangunan, dan sebaliknya, ilmu pembangunan diterapkan untuk mengatasi permasalahan pembangunan. Dalam tataran global maupun nasional, proses pembangunan berada dalam arus utama (mainstream) pembangunan ekonomi, bahkan pembangunan ekonomi disetarakan dengan pembangunan, 
padahal tentunya sangat berbeda. Dalam pembangunan ekonomi, hasil-hasil pembangunan cukup diukur berdasarkan indikator-indikator ekonomi. Keberhasilan pembangunan suatu wilayah di Indonesia diukur dengan indikator ekonomi saja, antara lain peningkatan Produk Domestik Regional Bruto (PDRB) dan pertumbuhan ekonomi. Dalam perspektif pembangunan ekonomi, luas hutan yang semakin menurun, peningkatan erosi, kualitas udara yang menurun, peningkatan emisi gas rumah kaca tidak menjadi indikator pembangun ekonomi.

Perjalanan panjang proses pembangunan dengan menggunakan pembangunan ekonomi sebagai mekanisme utamanya telah mengakibatkan berbagai permasalahan sosial dan lingkungan, antara lain meningkatnya emisi gas rumah kaca, terutama setelah revolusi industri di abad 18. Akhirnya pada tahun 1960 an, terbit buku yang terkenal, berjudul The Silent Spring karya Rachael Carson (1962) kemudian pada tahun 1972 dilaksanakan United Nations (UN) Stockholm Conference on the Human Environment, dan Brundtland Report pada tahun 1987 yang membawa konsep baru tentang pembangunan, yakni dikenal dengan istilah pembangunan berkelanjutan. Berdasarkan Laporan Brundtland (1987) pembangunan berkelanjutan didefinisikan sebagai berikut: "sustainable development in simple terms as paths of progress which meet the needs and aspiration of present generation without compromising the ability of the future generations to meet their own needs" (Brundtland, 1987). Sebelum tahun 1972, sebenarnya definisi pembangunan berkelanjutan telah banyak digunakan, bahkan mencapai 72 definisi (Rogers, Jalal, \& Boyd, 2008). Kemudian isu pembangunan berkelanjutan terus berkembang, disusul dengan Earth Summit tahun 1992 di Rio Janeiro atau UN Conference on Environment and Development (UNCED).

Paradigma pembangunan global telah berubah, dari pembangunan ekonomi menjadi pembangunan berkelanjutan. Indonesia sebagai bagian dari masyarakat global, tidak akan terlepas dari perubahan global, demikian juga pada tingkat lokal, bahkan individu, akan terpengaruh dan mempengaruhi. Pembangunan perlu dilaksanakan secara seimbang antara aspek ekonomi, sosial, dan lingkungan. Para aktor pembangunan sudah saatnya dan sudah 
seharusnya meninggalkan ego-sektoral yang hanya mengedepankan kepentingan jangka pendek sektor atau kelompoknya saja, namun sebaliknya harus berfikir jangka panjang, holistik dan dinamis, atau dinamakan berfikir sistem, yang dalam dunia ilmiah disebut sebagai Systems Thinking. Penelitian ini ditujukan untuk memperoleh prinsip-prinsip transformasi kebijakan pengendalian perubahan iklim dan pembangunan berkelanjutan berdasarkan paradigma Systems Thinking.

\section{METODE PENELITIAN}

Penelitian ini menggunakan Metode SSM (Soft System Methodology), suatu metode untuk menghadapi berbagai permasalahan atau situasi yang kompleks yang berdasarkan pada paradigm Systems Thinking, khususnya pendekatan soft system. Metode SSM digunakan untuk melakukan perbaikan situasi atau penyelesaian permasalahan dengan melalui learning system, yaitu melakukan refleksi terhadap objek situasi secara terorganisir dan berorientasi memperoleh aksi perbaikan atau solusi (Checkland, 2000).

Systems Thinking adalah paradigma atau cara memandang terhadap fenomena atau masalah sebagai suatu sistem. Sistem didefinisikan sebagai kumpulan dari bagianbagian yang bekerja secara bersama-sama untuk tujuan tertentu (Forrester, 1971). Sistem adalah sekumpulan unsur yang saling berhubungan, bergantung, dan berinteraksi untuk melakukan suatu fungsi (Soesilo \& Karuniasa, 2014).

General System Theory diperkenalkan oleh (Bertalanffy, 1968), yang antara lain menyatakan prinsip open system, bahwa setiap sistem/subsistem/unsur sistem tidak terbebas dari perilaku mempengaruhi maupun dipengaruhi sistem/subsistem/unsur lainnya. Dalam berfikir sistem selalu dihadapkan pada kompleksitas sistem yang ada di Dunia nyata baik detail complexity maupun dynamic complexity, oleh karena itu dibutuhkan penyederhanaan berfikir dalam Systems Thinking. Penyederhanaan detail complexity berarti mengurangi dan/atau menggabungkan unsur sistem, sedangkan penyederhanaan dynamic complexity berarti mengurangi kompleksitas hubungan antar unsur sistem (Gambar 1). 


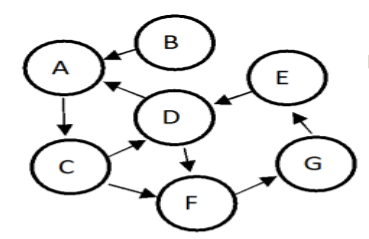

Detail Complexity tinggi

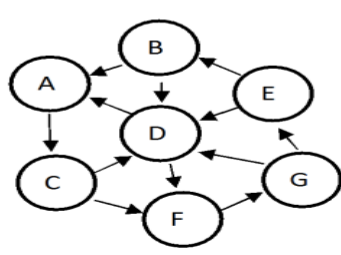

Dynamic Complexity tinggi
Penyederhanaan sistem
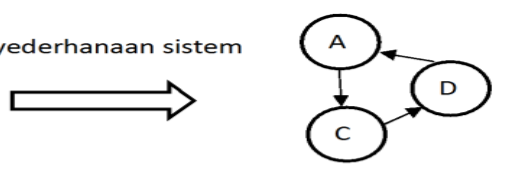

Detail Complexity rendah

Penvederhanaan sistem
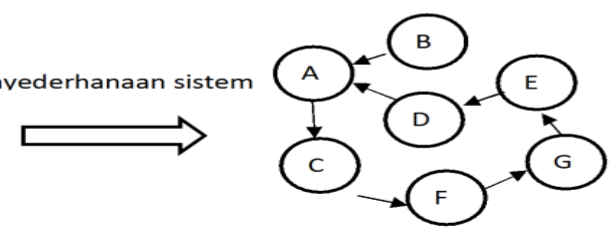

Dynamic Complexity rendah

Sumber: (Soesilo \& Karuniasa, 2014)

Gambar 1. Penyerhanaan Kompleksitas Sistem dalam Systems Thinking

Berdasarkan paradigma Systems

menggunakan pendekatan learning system atau Thinking Pembangunan dapat dipandang sebagai suatu sistem melalui dua pendekatan, yaitu hard system dan soft system (Karuniasa, 2016). Hard system menggunakan pendekatan sistem yang sebenarnya di Dunia nyata (misalnya sistem ekonomi, sistem sosial, ekosistem), sedangkan soft system

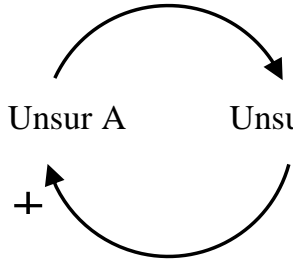

(i) Mendorong

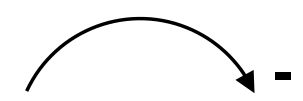

Unsur B

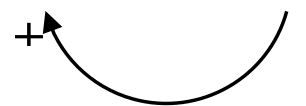

(ii) Menyeimbangkan

Pendekatan Hard System suatu sistem refleksi/pembelajaran terhadap suatu fenomena (Gambar 2). System Dynamics adalah metode yang dikembangkan oleh J. W. Forester berdasarkan pendekatan hard system, sedangkan Checkland (2000) mengembangkan Soft System Methodology dengan pendekatan soft

system.

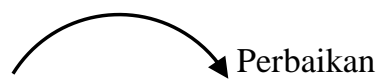

Para Pihak Situasi Pembangunan

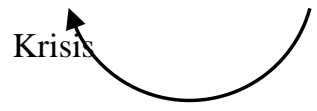

(iii) Konstruktif

Pendekatan Soft System

Sumber: (Karuniasa, 2017)

Gambar 2. Pendekatan Systems Thinking dan Prinsip Umpan Balik (Feedback) 
Prinsip proses pembangunan yang yang menjadi inti utama sistem pembangunan

dikonstruksikan dengan paradigma Systems

Thinking adalah pengendalian umpan balik
(Karuniasa, 2016) seperti terlihat pada Gambar 3.

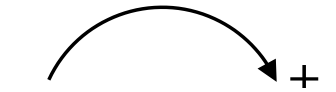

Unsur A Unsur B

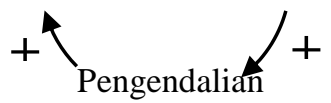

(i) Umpan balik mendorong

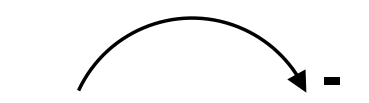

Unsur A

Unsur B

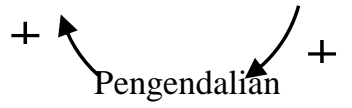

(ii) Umpan balik Menyeimbangkan Pendekatan Hard System
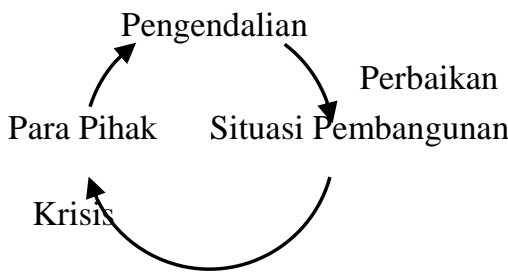

(iii) Umpan balik Konstruktif Pendekatan Soft System

Sumber: (Karuniasa, 2016)

Gambar 3. Prinsip Pengendalian Umpan Balik dalam Sistem Pembangunan

Sistem ekonomi mengikuti perilaku reinforcing feedback atau umpan balik mendorong (Gambar 3i). Sebagai contoh jika Unsur A adalah PDRB dan Unsur B adalah Investasi, maka semakin besar investasi akan mendorong peningkatan PDRB dan sebaliknya. Pengendalian dilakukan agar mekanisme sistem ekonomi menghasilkan pertumbuhan ekonomi, tidak terlalu tinggi maupun terlalu rendah. Hubungan ekonomi dan sumber daya alam mengikuti perilaku balancing feedback atau umpan balik menyeimbangkan (Gambar 3ii). Jika Unsur A adalah PDRB dan Unsur B adalah ketersediaan sumber daya alam, maka semakin tinggi ketersediaan sumber daya alam akan meningkatkan PDRB, sebaliknya peningkatan
PDRB akan mengakibatkan deplesi sumber daya alam. Pengendalian dilakukan untuk menjaga keberlanjutan sumber daya alam maupun PDRB itu sendiri. Dalam pendekatan soft system, situasi pembangunan dieksplorasi untuk menggali (inquiry) permasalahan maupun krisis yang terjadi dalam pembangunan (Gambar 3iii), selanjutnya dicerna oleh para pihak untuk melakukan tindakan pengendalian situasi pembangunan melalui aksi perbaikan. Proses ini terjadi terus menerus melalui mekanisme sistem pembelajaran (learning system) dan menghasilkan perbaikan situasi pembangunan yang layak dan dapat diterima, bahkan juga menghasilkan perbaikan dalam penggalian 
(inquiry) permasalahan dan krisis pembangunan maupun perbaikan dalam aksi perbaikan (leaning system) itu sendiri.

\section{HASIL DAN PEMBAHASAN}

\section{Refleksi Pola Pembangunan Nasional,} Pembangunan Berkelanjutan, dan

\section{Perubahan Iklim}

Jumlah penduduk Indonesia terus meningkat, dari 119,2 juta pada tahun 1971 menjadi 237,6 juta pada tahun 2010, dan diperkirakan pada tahun 2018 mencapai 265,0 juta (BPS, 2013). Dengan jumlah penduduk yang terus bertambah, kebutuhan air, pangan, pakaian, tempat tinggal, energi, dan kebutuhan barang primer terus bertambah. Populasi beserta kebutuhannya, melalui pola pembangunan saat ini, memberikan tekanan terhadap sumber daya alam dan jasa lingkungan yang sebaliknya berpengaruh pada penyediaan ketersediaan pangan, air, dan energi yang itu sendiri. Diperkirakan pada tahun 2035 jumlah penduduk Indonesia akan mencapai 305,6 juta jiwa (BPS, 2013), yang berarti permintaan kebutuhan dasar terus meningkat terutama air, pangan, dan energi.
Upaya untuk meningkatkan kemampuan investasi, memenuhi kebutuhan barang, belanja pemerintah, dan ekspor, dibutuhkan pembangunan di bidang ekonomi, apalagi untuk mengejar ketertinggalan dari negara lain, khususnya negara tetangga. Sebagai contohnya Indonesia masih tertinggal dengan Singapura, Vietnam, Thailand, dan Malaysia dalam hal eksport, dan Produk Domestik Bruto (PDB) perkapita juga berada di urutan ke 5 setelah Singapura, Brunei Darussalam, Malaysia, dan Thailand (Gambar 4). Sangat rasional Indonesia berupaya mengejar ketertinggalan pembangunan ekonomi dari negara tetangga, maupun untuk berkembang menjadi negara maju. 


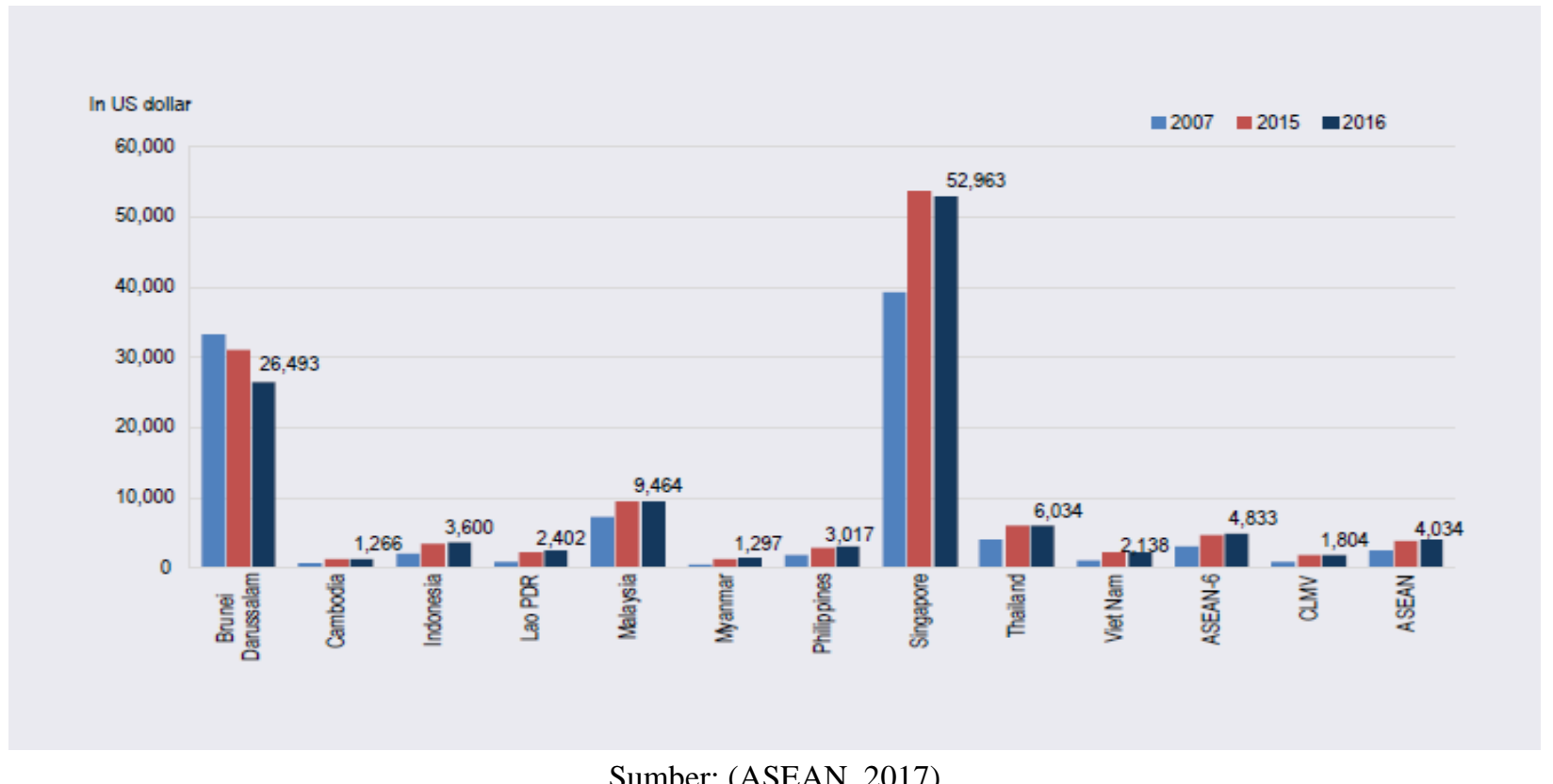

Sumber: (ASEAN, 2017)

Gambar 4. Perbandingan Produk Domestik Bruto (PDB) Perkapita Negara Anggota ASEAN

Namun demikian, dalam upaya meningkatkan kondisi perekonomian maupun mengejar ketertinggalannya, pembangunan di Indonesia masih menunjukkan pola pembangunan nasional yang tidak berkelanjutan (Gambar 5). Semakin berhasil pembangunan ekonomi suatu provinsi yang diukur dengan tingginya Produk Domestik Regional Bruto (PDRB), diikuti nilai Indeks Pembangunan Manusia (IPM) yang juga cenderung meningkat, namun ternyata sebaliknya kualitas lingkungan hidup cenderung mengalami penurunan yang ditunjukkan dengan Indeks Kualitas Lingkungan Hidup (IKLH). Pembangunan yang tidak berkelanjutan mengakibatkan banyak permasalahan lingkungan, seperti deforestasi, lahan kritis, banjir, kekeringan, krisis air bersih, pencemaran, emisi gas rumah kaca, dan lainnya. Secara keseluruhan, pembangunan yang tidak berkelanjutan mengakibatkan deplesi kapital alam yang terdiri atas sumber daya alam dan jasa lingkungan.

Pembangunan berkelanjutan dilandasi dari dua teori besar, yaitu teori pembangunan 
dan teori sustainability atau keberlanjutan. Miller \& Spoolman (2012) mendefinisikan bahwa "sustainability is the ability of the earth's various systems, including human cultural systems and economies, to survive and adapt to changing environmental indefinitely" (kemampuan sitem pendukung kehidupan termasuk sistem kehidupan manusia dan ekonomi untuk tetap dapat bertahan dan beradaptasi menghadapi perubahan kondisi lingkungan secara terus-menerus) (Miller \& Spoolman, 2012). Oleh karena itu, dalam pembangunan

pembangunan mengorbankan kondisi sosial dan lingkungan, sebaliknya upaya menjaga atau melestarikan lingkungan juga tidak dapat mengorbankan aspek ekonomi, artinya pembangunan ekonomi, sosial, dan lingkungan harus seimbang dan selaras. Pola pembangunan nasional perlu dirubah, agar peningkatan kondisi perekonomian selalu diiringi dengan peningkatan maupun terjaganya kualitas lingkungan hidup.

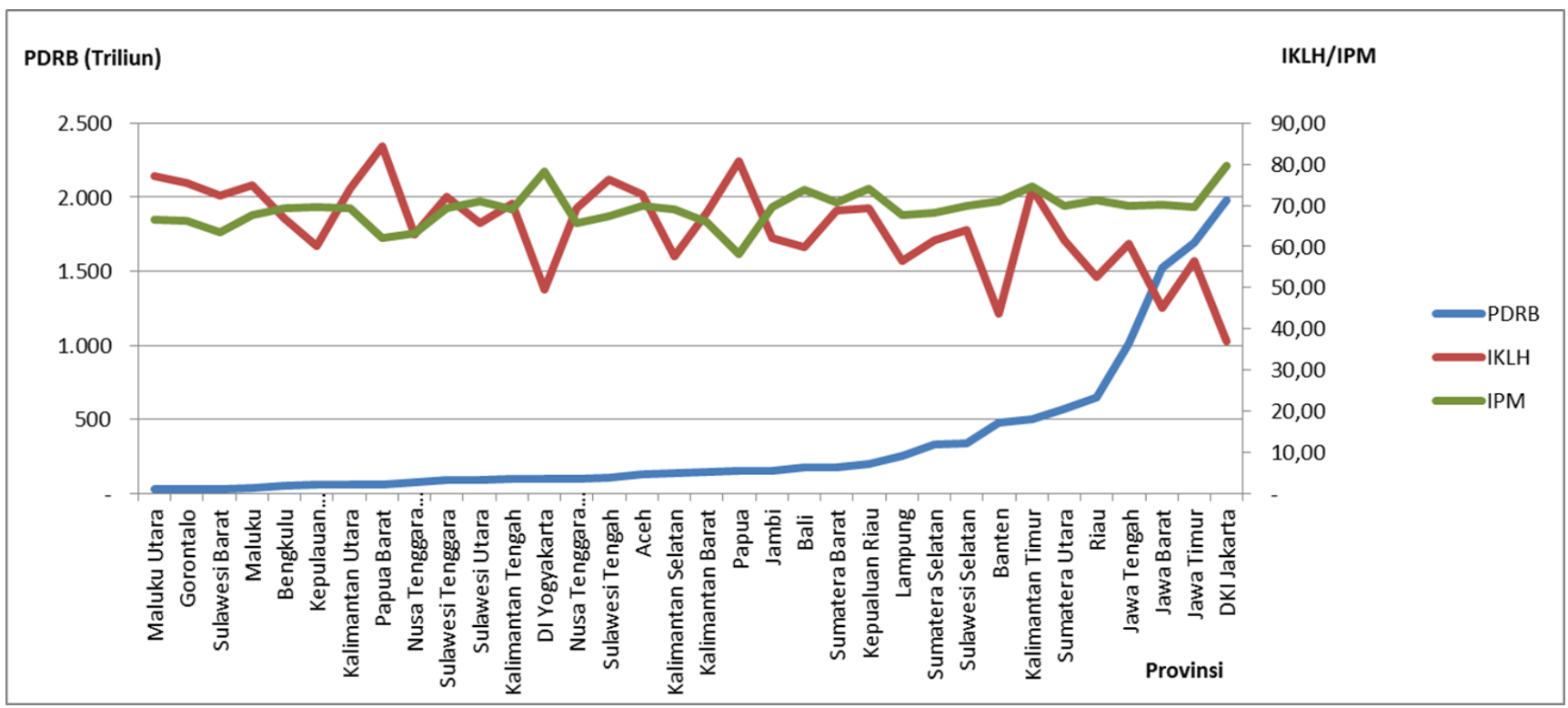

Keterangan:

PDRB = Produk Domestik Regional Bruto (tahun 2015)

IKLH = Indeks Kualitas Lingkungan Hidup (tahun 2015)

IPM = Indeks Pembangunan Manusia (tahun 2015)

Gambar 5. Pola Pembangunan Nasional 
Pola pembangunan nasional yang tidak berkelanjutan juga berimplikasi pada emisi gas rumah kaca nasional. Berdasarkan emisi gas rumah kaca nasional sejak tahun 2000, terlihat kecenderungan peningkatan emisi gas rumah kaca dengan pola yang masih berada pada jalur business as usual (BAU) sesuai proyeksi emisi di tahun 2030 (Gambar 6). Pada tahun 2010 emisi gas rumah kaca sebesar 1,12 giga ton $\mathrm{CO}_{2}$ ekuivalen, meningkat pada tahun 2015 menjadi 1,995 giga ton $\mathrm{CO}_{2}$ ekuivalen. Tanpa perubahan pola pembangunan, khususnya terkait dengan kebijakan pengendalian perubahan iklim, diperkirakan pada tahun 2030 emisi gas rumah kaca akan mencapai 2,87 giga ton $\mathrm{CO}_{2}$ ekuivalen. Kebijakan pegendalian perubahan iklim juga membutuhkan pendekatan yang holistik, agar upaya mitigasi dan adaptasi pada saat yang bersamaan meningkatkan perekonomian dan kesejahteraan sosial. Sebaliknya juga untuk memastikan bahwa pembangunan ekonomi dan upaya peningkatan kesejahteraan sosial meningkatan resiliensi dan mereduksi emisi gas rumah kaca.

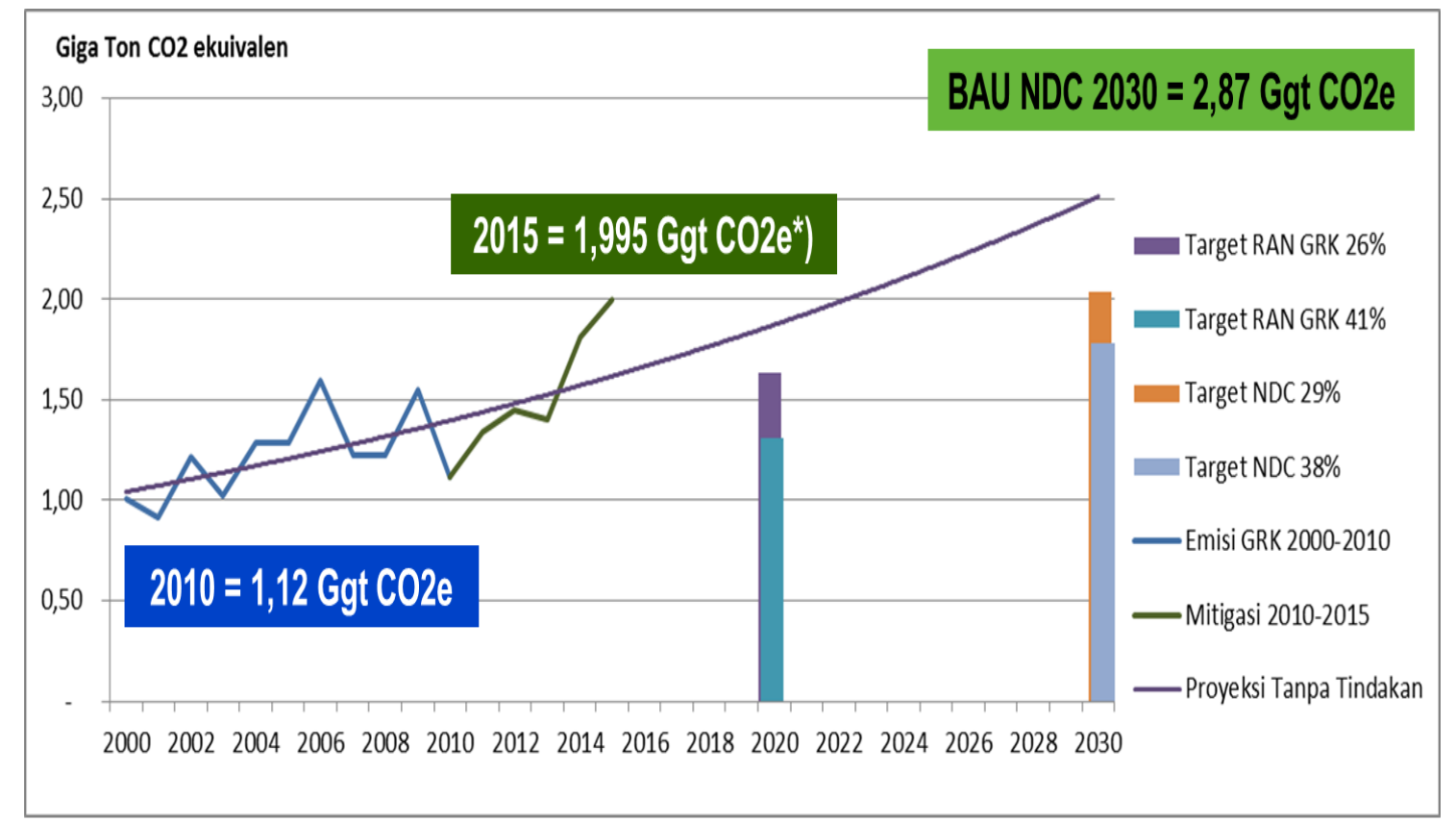

Keterangan: NDC = Nationally Determined Contribution, RAN GRK = Rencana Aksi Pengurangan Emisi Gras Rumah Kaca

$B A U=$ Business as Usual (proyeksi tanpa pengendalian perubahan iklim)

*) angka sementara

Gambar 6. Emisi Gas Rumah Kaca Nasional 2000-2015 


\section{Refleksi Kebijakan Perlindungan dan}

\section{Pengelolaan Lingkungan Hidup}

Di negara berkembang, termasuk Indonesia, peran pemerintah masih menjadi pilar utama dalam pembangunan. Kebijakan pemerintah menjadi instrumen penting kelembagaan pembangunan, dan dalam konteks lingkungan hidup, Undang-Undang Nomor 32 Tahun 2009 Tentang Perlindungan dan Pengelolaan Lingkungan Hidup (UU 32 Tahun 2009) menjadi landasan hukum pengelolaan lingkungan hidup. Melalui UU 32 Tahun 2009 diharapkan pembangunan nasional tidak meninggalkan aspek lingkungan hidup, atau dalam kata lain menjadi instrumen untuk mewujudkan pembangunan berkelanjutan.

Isu lingkungan global saat ini adalah perubahan iklim dan pembangunan berkelanjutan. Instrumen global yang disepakati oleh para pihak, termasuk Indonesia yaitu Nationally Determined Constribution (NDC) untuk perubahan iklim dan Sustainable Development Goals (SDGs) untuk pembangunan berkelanjutan. Indonesia telah maratifikasi Paris Agreement yang menyepakati skema NDC dengan UndangUndang No. 16 tahun 2016 pada tanggal 24
Oktober 2016. Artinya Indonesia berkomitmen mengurangi emisi gas rumah kaca sebesar $29 \%$ dengan kemampuan sendiri dan 38\% sampai dengan $41 \%$ melalui kemitraan internasional pada tahun 2030. Pemerintah Indonesia juga telah mengeluarkan Peraturan Pemerintah Nomor 59 tahun 2017 Tentang Pelaksanaan pencapaian tujuan Pembangunan Berkelanjutan, dan berkomitmen untuk mencapai 17 tujuan, 169 target dan 241 indikator global SDGs. Sebagai bagian dari masyarakat international, tentu saja menjadi keharusan untuk mewujudkan komitmennya baik dalam isu perubahan iklim maupun pembangunan berkelanjutan. Namun yang lebih penting adalah bagaimana menyelaraskan pencapaian komitmen dengan upaya pembangunan berkelanjutan nasional yang sesuai dengan kondisi ekologis, sosial, dan perekonomian Indonesia, dengan prinsip dasar sustainability.

Di dalam UU 32 Tahun 2009 terdapat instrumen kebijakan penting yang memiliki peluang untuk membantu mewujudkan perubahan pola pembangunan dari yang tidak berkelanjutan menjadi pembangunan yang berkelanjutan. Instrumen tersebut adalah 
Kajian Lingkungan Hidup Strategis (KLHS). Pada pasal 15 UU 32 Tahun 2009, pembuatan KLHS adalah untuk memastikan bahwa prinsip pembangunan berkelanjutan telah menjadi dasar dan terintegrasi dalam pembangunan suatu wilayah dan/atau kebijakan, rencana, dan/atau program. Implementasi KLHS masih menghadapi banyak tantangan, antara lain masih dianggap sebagai analisis mengenai dampak lingkungan hidup (AMDAL) dari kebijakan, rencana, dan program (KRP) atau AMDAL KRP, bukan diselenggarakan sebagai kajian pembangunan berkelanjutan. Tantangan yang lebih substansial adalah paradigma parsial/sektoral, sesaat/jangka pendek, serta berfikir statis atau tidak mempertimbangkan perubahan (tidak dinamis). Nilai-nilai para pengambil keputusan dan pemangku kepentingan berperan penting dalam KLHS (Danida, 2017) dan Dusik et al. (2010) mencatat pentingnya peran pengambil keputusan dan pemangku kepentingan. Sangat sedikit KHLS yang melakukan kajian keberlanjutan dan umumnya menggunakan analisis daya dukung lingkungan hidup saja serta bersifat statis dan sesaat (Karuniasa, 2018). Dalam rangka membangun nilai-nilai sustainability, pengambil keputusan dan para pemangku kepentingan membutuhkan perubahan skema konseptual atau paradigma.

\section{Prinsip-Prinsip Kebijakan Pembangunan}

Berkelanjutan dan Pengendalian Perubahan Iklim

Hak asasi setiap warga negara Indonesia atas lingkungan hidup yang baik dan sehat, serta pembangunan berkelanjutan adalah pertimbangan utama atau menjadi konteks UU 32 Tahun 2009 sebagai kebijakan perlindungan dan pengelolaan lingkungan hidup. Disisi lain, sampai dengan saat ini pola pembangunan nasional masih tidak berkelanjutan. Upaya strategis untuk mewujudkan pembangunan berkelanjutan di Indonesia dibutuhkan, pertama, perubahan paradigma dari parsial/sektoral yang statis dan sesaat menjadi paradigma Systems Thinking yang holistik dan dinamis, khususnya untuk para pemangku kepentingan, terutama pengambil keputusan di pemerintahan. Kedua, perlu dibangun kesadaran dan tindakan operasional para pemangku kepentingan, termasuk pemerintah, bahwa UU 32 Tahun 2009 adalah dalam konteks pembangunan berkelanjutan untuk 
mewujudkan Indonesia berkelanjutan. Ketiga, dalam menghadapi isu global, seperti perubahan iklim dan SDGs, perlu dikonstruksikan sesuai kondisi ekonomi, sosial, dan lingkungan baik di tingkat nasional maupun subnasional, termasuk kaitannya dalam hal penggunaan teknologi terkini (Putra et al., 2018)

Berbagai kerusakan lingkungan maupun terganggunya ekonomi karena terdegradasinya sumber daya alam dan jasa lingkungan yang terjadi saat ini menjadi momentum untuk melakukan perubahan paradigma parsial/sektoral yang statis dan sesaat menjadi paradigma Systems Thinking yang holistik dan dinamis. Dampak kerusakan lingkungan akibat kegiatan ekonomi, serta sebaliknya, dampak ekonomi akibat degradasi sumber daya alam dan jasa lingkungan maupun kerusakan lingkungan lainnya semakin jelas. Sebagai contoh sistem pertanian konvensional yang masih terus memberikan input kimiawi baik pupuk maupun pengendalian organisme pengganggu tanaman (OPT) yang berkontribusi terhadap emisi gas rumah kaca (Pambudi \& Waryono, 2018). Selain itu, degradasi ekosistem di kawasan sumber air juga semakin nampak dan mulai menimbulkan kekhawatiran bagi masyarakat (Karuniasa \& Pambudi, 2019). Tuntutan atau permintaan atas kondisi lingkungan yang baik dan sehat sudah semakin meningkat, meskipun penawaran aspek tersebut masih sangat terbatas. Kondisi lingkungan yang baik dan sehat juga belum menjadi komoditas tawar-menawar antara politisi dan konstituennya, namun hal ini tidak akan bertahan lama. Tidak akan lama lagi, kualitas lingkungan hidup, serta perlindungan dan pengelolaan lingkungan hidup, seperti ketersediaan air, pangan, dan energi akan menjadi komoditas politik.

Perlindungan dan pengelolaan lingkungan hidup melalui instrumen kebijakan UU 32 Tahun 2009 maupun kebijakan turunannya, masih diangap oleh berbagai pihak sebagai instrumen lingkungan hidup dalam arti sempit. Padahal jelas bahwa konteknya adalah pembangunan berkelanjutan, atau setidaknya pembangunan ekonomi yang berwawasan lingkungan. Pemahaman dan implementasi kebijakan perlindungan dan pengelolaan lingkungan hidup masih mengambil posisi berseberangan dengan pembangunan ekonomi. Sebaliknya para pihak/institusi diluar 
Kementrian Lingkungan Hidup dan Kehutanan (KLHK) masih menganggap UU 32 tahun 2009 adalah urusan KLHK saja. Pemahaman ini menciptakan situasi, bahwa perlindungan dan pengelolaan lingkungan hidup dianggap menghambat pembangunan ekonomi, dan sebaliknya pembangunan ekonomi dianggap sebagai hambatan perlindungan dan pengelolaan lingkungan hidup. Implementasi KLHS yang bersifat inklusif dan berdasarkan pada kaidah kajian keberlanjutan, memberikan peluang kepada para pemangku kepentingan termasuk pemerintah untuk membangun kesadaran dan melakukan tindakan operasional pembangunan berkelanjutan, termasuk dalam pengendalian perubahan iklim.

Upaya mitigasi gas rumah kaca dan adaptasi terhadap Perubahan iklim serta pencapaian target SDGs adalah instrumen global yang disepakati untuk menghadapi masalah bersama (common problems). Kondisi Indonesia berbeda dengan negara lainnya, baik ekonomi, sosial, dan lingkungan, demikian juga suatu wilayah pembangunan, baik provinsi maupun kabupaten di Indonesia, berbeda satu dengan lainnya secara ekologis, sosiologis, dan karakter kondisi ekonominya. Sehingga implementasi mitigasi dan adaptasi perubahan iklim, serta pencapaian SDGs perlu ditransformasikan ke dalam situasi dan kondisi pembangunan di Indonesia baik tingkat nasional dan subnasional. Komitmen Indonesia melalui skema NDC meliputi 5 sektor, yaitu sektor NDC Energi, Limbah, IPPU (Industrial Process and Product Uses), Pertanian, dan Kehutanan. Melalui paradigma System Thinking, upaya mitigasi gas rumah kaca sektor NDC Energi pada saat yang sama harus mampu memenuhi kebutuhan energi, seperti peningkatan elektrifikasi. Reduksi emisi dari sektor NDC Pertanian, pada saat yang sama juga harus mempertahankan atau meningkatkan ketahanan pangan. Demikian juga dalam implementasi SDGs, 17 tujuan, 169 target, dan 241 indikator, perlu ditempatkan sesuai konteks Indonesia baik nasional maupun pada masingmasing wilayah pembangunan di tingkat daerah. Sehingga pengendalian perubahan iklim dan pembangunan berkelanjutan pada tingkat nasional dan subnasional dikonstruksikan berdasarkan kondisi ekonomi, sosial, dan lingkungan, selanjutya dikomunikasikan menggunakan instrumen NDC dan SDGs untuk mendukung upaya 
pembangunan berkelanjutan global, bukan sebaliknya.

\section{KESIMPULAN DAN SARAN}

\section{A. Kesimpulan}

Selain untuk mendukung jumlah penduduk yang terus bertambah, Indonesia masih perlu berupaya mengejar ketertinggalan pembangunan ekonomi baik dari negara tetangga, maupun untuk berkembang menjadi negara maju. Namun demikian, pembangunan nasional yang dilakukan masih menunjukkan pola pembangunan yang tidak berkelanjutan. Upaya untuk mewujudkan pembangunan berkelanjutan dan pengendalian perubahan iklim di Indonesia, dibutuhkan prinsip-prinsip transformasi kebijakan. Pertama, perubahan paradigma dari parsial/sektoral yang statis dan sesaat menjadi paradigma Systems Thinking yang holistik dan dinamis, khususnya untuk para pemangku kepentingan, terutama pengambil keputusan di pemerintahan. Kedua, perlu dibangun kesadaran dan tindakan operasional para pemangku kepentingan, termasuk pemerintah, bahwa UU 32 Tahun 2009 adalah dalam konteks pembangunan berkelanjutan untuk mewujudkan Indonesia berkelanjutan. Ketiga, dalam menghadapi isu global, seperti perubahan iklim dan SDGs, perlu dikonstruksikan sesuai kondisi ekonomi, sosial, dan lingkungan baik di tingkat nasional maupun subnasional.

\section{B. Saran}

Mempertimbangkan penelitian ini menghasilkan prinsip-prinsip transformasi kebijakan yang bersifat umum, maka perlu dilakukan penelitian lebih lanjut yang lebih operasional. Namun juga dapat menjadi pedoman umum penyusunan kebijakan pembangunan berkelanjutan dan pengendalian perubahan iklim.

\section{UCAPAN TERIMA KASIH}

Penelitian ini terinspirasi dari pengalaman belajar dan mengajar di Program Studi Ilmu Lingkungan Universitas Indonesia, serta berbagai kesempatan yang diperoleh melalui keterlibatan di pengendalian perubahan iklim nasional maupun internasional, penyusunan RAN SDGs Indonesia, juga dalam penyusunan kebijakan dan implementasi KLHS. Untuk itu diucapkan banyak terima kasih kepada Universitas Indonesia, KLHK, 
dan Sekretariat SDGs Indonesia. Ucapan terima kasih tentu saja juga disampaikan kepada Panitia Pre-Event $3^{\text {rd }}$ Asia Pasific Rainforest Summit dan Badan Litbang dan Inovasi KLHK, khususnya Puslitbang Sosial, Ekonomi, Kebijakan dan Perubahan Iklim yang memberikan peluang untuk memuat tulisan ini kedalam Jurnal Analisis Kebijakan Kehutanan (JAKK). Selain itu, terima kasih diucapkan kepada seluruh pihak yang memungkinkan terlaksananya penelitian dan penulisan jurnal ini.

\section{DAFTAR PUSTAKA}

ASEAN. (2017). One Vision One Identity One Community.

Bertalanffy, L.V. (1968). General System Theory. New York.: George Braziller, Inc.

BPS. (2013). Katalog BPS: 2101018. In Bps.

Brundtland, Report. (1987). Our Common Future. United Nations.

Carson, R. (1962). Silent Spring. Boston: Houghton Mafflin.

Checkland, P. (2000). Systems Thinking, Systems Practice: Includes a 30-Year Retrospective. The Journal of the Operational Research Society, 51(5), 647.
Danida. (2017). Strategic Environmental Assessment in Indonesia: Results and Lessons Learned from 10 years of Danish Support. Jakarta: Danida.

Dusik, J., Setiawan, B., Kappiantari, M., Argo T., Nawangsidi, H., Wibowo, S, A., Rustiadi, E., Djoekardi, A. (2010). Making SEA fit for political culture of strategic decision-making in Indonesia: Recommendation for General technical guidance on SEA. Jakarta.

Forrester J.W. (1971). Principles of Systems. Waltham.: Pegasus Communication, Inc.

Karuniasa, M. (2016). Holistic Approach in Practice: The Principles of National Sustainable Development System. School of Environmental Science. Jakarta: Universitas Indonesia.

Karuniasa, M. (2017). Kertas Kerja Rekomendasi Lingkungan Hidup, Badan Rembuk 8. Jakarta.

Karuniasa, M. (2018). Rangkuman Hasil Review Pakar dan Saran Tindak Lanjut Penyelenggaraan KLHS di Indonesia. Jakarta.

Miller, G, T., \& Spoolman, S, E. (2012). Living in The Environment. Seventeenth Edition. Canada.: Thompson Brooks/Cole,.

Putra, A., Rtnaningsih, A.T., \& Ikhwan, M. (2018). Pemetaan Daerah Rawan Kebakaran Hutan dan Lahan Dengan Menggunakan Sistem Informasi Geografis (Studi Kasus: Kecamatan Bukit Batu, 
Kab. Bangkalis, Wahana Forestra, 13(1), 55-63.

Karuniasa, M., \& Pambudi, P.A. (2019). Transition of Primary Forest to Secondary Forest and the Impact for Water Resources Conservation. Journal of Environmental Science and Sustainable Development, 2(1), 15-25.

Pambudi, P.A., \& Waryono, T. (2018). Life cycle assessment of dryland paddy farming in Ngadirojo District, Pacitan. IOP Conference Series: Earth and Environmental Science 07001, 1-7.

Peet, R., \& Hartwick, E. (2009). Theories of Development. Second Edition. New YorkLondon.: The Guilford Press.

Rogers, P.P., Jalal, K.F., \& Boyd, J.A. (2008). An Introduction To Sustainable Development. Earthscan. UK.

Soesilo, T.E.B., \& Karuniasa, M. (2014). Permodelan System Dynamics, Untuk Berbagai Bidang Ilmu Pengetahuan Kebijakan Pemerintah dan Bisnis. Jakarta: Lembaga Penerbit Fakultas Ekonomi Universitas Indonesia. 